\title{
Analysis on the Incentive Mechanism of Human Resources Management in the Public Sectors
}

\author{
Yang Yanhong \\ School of Public Finance and Management, \\ Yunnan University of Finance and Economics, Kunming, Yunnan, China \\ 407001835@qq.com
}

\begin{abstract}
The public sector is mainly responsible for providing public goods and services to the society. With the rapid development of economy, the public raise a high demands for the efficiency and quality of staffs in the public sectors. However, as far as the present situation is concerned, the efficiency and quality of public sector administration still in a low condition, the public satisfaction is not high. The lack of a reasonable and effective incentive mechanism is a crucial factor to reduce enthusiasm of public officials in their work, and further affect administrative efficiency in public sectors. Therefore, this paper aims to discusses how to further improve the human resources management incentive mechanism in the public sectors.
\end{abstract}

Keywords-public sector human resource management incentive

\section{INTRODUCTION}

The public sector is mainly responsible for providing public goods and services to the society. At present, the public not satisfied with the administrative efficiency and quality in public sector. The public officials lack a sense of responsibility, a good work state and efficiency. Therefore, it is particularly imperative to further improve the incentive mechanism of human resources management in the public sector.

\section{OVERVIEW OF HUMAN RESOURCES MANAGEMENT}

\section{INCENTIVES IN THE PUBLIC SECTORS}

The main purpose of human resource management in public sector is to stimulate the enthusiasm of public sector personnel, improve the performance of public sector, and achieve the strategic goal of public sector. It attaches importance to the management idea of "people first", emphasizes the incentive. With the help of the spirit and material incentive measures, to stimulate the work enthusiasm, initiative and creativity of the personnel, and then to improve the administrative efficiency and quality of the public sector.

The reason why the incentive mechanism is important is human resource management underlines the important of "human", and attaches great importance to stimulate the potentials and development of employees. For the factors of "human" are so important, it is imperative to establish and implement a perfect incentive mechanism so as to stimulate the enthusiasm of the staff and guide the staff's personal goals to the organizational goals by taking effective incentives, and further to improve the efficiency and quality of the public sector and achieve the ultimate goal of maintaining the common interests of the society. At present, public sector's worker in China still lacks sense of responsibility, work enthusiasm and even negative work conditions. The public complains the work efficiency and quality of the public sectors and have a low satisfaction. Ultimately, the public sectors have followed a relatively single incentive model for a long time, especially in terms of the distribution of income that employees are most concerned about, according to their position and rank, but this approach does not fully reflect the work loads, difficulty and performance. Therefore, the analysis of the shortcomings of the existing incentive model can provide a 
reference for further improving the incentive mechanism of human resources management in the public sector.

\section{PROBLEMS IN THE INCENTIVE OF HUMAN}

\section{RESOURCES MANAGEMENT IN THE PUBLIC SECTORS}

\section{A. The evaluation system is not scientific.}

First, the evaluation index system is not scientific enough. At present, although the assessment of workers in the public sector has been set up a score, whereas it is generally more emphasis on morality and learning, and the standard definition is rather vagueness, most of them are qualitative descriptions, and the assessment indicators are difficult to quantify. Actual examination is bound to be affected by certain subjective factors, so it is embrace a poor operating ability. Second, the fairness and rationality of evaluation is not perfect. It is difficult to refine all kinds of indicators to carry out quantitative assessment. The existing assessment and evaluation models are greatly influenced by subjective factors, the main body of examination is relatively single, and most of them are mainly self-evaluation and superior leaders' assessment. This leads to some jobs and the leadership of the more closely connected personnel naturally get a higher rating. At the same time, due to the lack of other related groups, such as service objects, colleagues participate in the examination, its fairness and rationality is questioned.

\section{B. Income distribution mechanism is still not reasonable.}

At present, the public sector in China generally adopts a relatively solidified salary system at the post level, which mainly corresponds to the income at the post and rank levels, while the income not proportional to the workload, the difficulty of work, the consumption of working time, and the work effort, Work contribution and so on. On the one hand, the same rank may have difficulty and complexity, on the other hand, many grass-roots workers work more and pay more, thus seriously lacking incentives. This makes it difficult to mobilize the initiative of the grassroots.

\section{C.The promotion mechanism is not perfect.}

A reasonable and effective promotion mechanism is also a positive incentive mechanism, which can stimulate the public sector's staffs to exert their ability and promote the enthusiasm and pioneering nature of the work. At present, the promotion incentive mechanism in the public sector organizations is not scientific or reasonable enough, the phenomenon of "appotism" and "seniority" still exists. Due to the lack of competition and the single channels for promotion, the situation of "being able to rise or not to fall" is relatively common, and it is difficult to achieve promotion across departments which restricts the talent development and reduce the enthusiasm of public officials to carry out the work.

\section{D.Staff flow channels have not been effectively opened.}

At present, the public sector in China is not sufficiently to spread according to the specific talents of civil servants, which is relatively rigid. It is generally difficult to change once we enter a certain post, although the public sector personnel are interested in their careers because of their personal talents. Professional competence is different, or consideration given to career development, and there is a willingness to move. At the same time, some public sectors also lack or are short of relevant personnel, but are limited by factors such as establishment, position, unit, treatment, and exchange of personnel. Flow channel is relatively closed, dynamic grasp of departmental knowledge, expertise, skills and through effective mobility to achieve the best match due to lack of personal ability, identity, sense of achievement and motivation of work.

\section{SOME SUGGESTIONS ON PERFECTING THE INCENTIVE}

\section{MECHANISM OF HUMAN RESOURCES MANAGEMENT IN} PUBLIC SECTOR

\section{A.The Assessment and Evaluation of Mechanism}

A reasonable and effective evaluation mechanism plays an important role to encourage civil servants. It is necessary to establish a set of fair and reasonable performance appraisal system with emphasis on work ability and work performance, and evaluate it through effective, fair and reasonable assessment. We can draw lessons from the 
enterprise human resources management incentive assessment system, scientifically and reasonably formulate the assessment standard, as far as possible refine the assessment index to establish a quantitative assessment system, avoid subjective factors interference. At the same time, to cover serve the object, Colleagues' assessment of the staff in the assessment value, it can be a more reasonable and comprehensive evaluation. In particular, it is imperative to gradually perfect the performance appraisal system. The results of the appraisal should be linked to the performance pay, so that everyone's return should be consistent with the individual ability and work input. Pay attention to the assessment of work efficiency, effect, ability to handle affairs, working status, working intensity, etc. So as to makes sure that the civil servants with outstanding ability and achievement get approved. The civil servants with mediocre and backward achievements have the sense of crisis, and play the role of incentive of the appraisal and evaluation mechanism.

\section{B.Remuneration system}

First, to improve the income distribution system, appropriately expand the income gap within the industry, make full use of the performance-based wage system, reflect different performance levels in line with the ability to work, take responsibility and implement a flexible performance-based wage system vigorously play the role of compensation incentives. The second is the implementation of differentiated pay increases. The public sector has implemented a fixed wage system for a long period of time. Along the reform of the salary system, the state policy has given some of the salary increases to the same standard according to the promotion situation and the increase in the number of years of service. Some pay according to the position, not considering the working years, load, difficulty, and so on, differentiated pay increase can be based on the actual situation, reflect the principle of good work deserves good pay, which is conducive to the mobilization of enthusiasm and play the role of incentive pay.

\section{The promotion and mobility of the public servant}

As for personnel mobility, we shall strive to coordinate the various matching measures so as to form a more flexible mobility mechanism, and in the process of mobility, On the one hand, they, according to personal professional ability, career planning, career interest and so on, can choose posts that are more suitable for themselves, and encourage civil servants with outstanding professional abilities to go to more promising departments so as to play a greater role. On the other hand, there should be a corresponding elimination mechanism to dissolve those who can't adapt to their own work or performance mediocre or even backward civil servants.

\section{CONCLUSION}

Through the above discussion, the scientific and reasonable formulation and the apply of public sector human resources management incentive mechanism and related corresponding systems can effectively play the role of incentives to guide staff behavior in line with the organizational goals, and further enhance the efficiency of the public sectors and and force the satisfaction with the public goods and services provided by the public sectors so as to gain good social benefits.

\section{REFERENCE:}

[1] Fan Lijuan. He Jing. Incentive in Human Resource Management of the Public Sectors in China[J].Management manager,2014.

[2] Liu Feng. Research on Incentive Mechanism of Human Resource Management in the Public Sectors[J].Research on the Financial and Economic issues ,2013.

[3] Wang Chengwei. Obstacles and Countermeasures of incentive Mechanism of Human Resources Management in the Public Sectors[J].Journal of Northeast University of Finance and Economics ,2012

[4] Zhao Qiucheng. Yang Xiuling. Cao Jing .Human Resource Management in the Public Sectors [M].Beijing : Tsinghua University Press, 2014 